\title{
Análise endogâmica de uma população de pepino caipira
}

\author{
Amanda Regina Godoy; Victoria Rossmary S. Oviedo; Antonio Ismael Inácio Cardoso \\ UNESP/FCA, Depto. Produção Vegetal, C. Postal 237, 18603-970 Botucatu-SP; E-mail: amandaregina@fca.unesp.br
}

\begin{abstract}
RESUMO
Neste trabalho avaliou-se a perda de vigor para produção de frutos imaturos com sucessivas gerações de autofecundação $\left(\mathrm{S}_{0}, \mathrm{~S}_{1}, \mathrm{~S}_{2}\right.$, $\mathrm{S}_{3}, \mathrm{~S}_{4}$ e $\mathrm{S}_{5}$ ), em uma população de pepino caipira, obtida pelo cruzamento dos híbridos Safira x Hatem. O delineamento experimental utilizado foi em blocos ao acaso, sete tratamentos (seis gerações de autofecundação com diferentes níveis de endogamia e o híbrido Safira como testemunha), seis repetições e cinco plantas por parcela conduzidas em ambiente protegido. Foram avaliados a produção de frutos imaturos total e comercial (número e peso), porcentagem de frutos comerciais e peso médio de frutos. As médias foram comparadas pelo teste de Tukey (5\%) e a avaliação da depressão por endogamia foi feita com análise de regressão sem o híbrido Safira. As populações $S_{0}$ e $S_{1}$ foram iguais ou superiores ao híbrido Safira para as características número de frutos totais, peso total por planta e peso de frutos comercial por planta, demonstrando o potencial desta população para obtenção de uma nova cultivar ou híbrido do tipo caipira. Houve menor produção de frutos (total e comercial) a partir da população $S_{2}$, demonstrando possível perda de vigor nesta população com as autofecundações sucessivas.
\end{abstract}

Palavras-chave: Cucumis sativus, endogamia, produção, melhoramento.

\begin{abstract}
Inbreeding depression in a "caipira" cucumber population

In this work we evaluated the inbreeding depression on immature fruit yield with successive generations of self-pollination $\left(S_{0}, S_{1}, S_{2}\right.$, $\mathrm{S}_{3} ; \mathrm{S}_{4}$ and $\mathrm{S}_{5}$ ), in a cucumber population 'caipira' type obtained by crossing Safira $x$ Hatem hybrids. The experimental design was of randomized blocks, seven treatments (different generations of self pollination: $S_{0}$ to $S_{5}$ and the hybrid Safira), six replicates and five plants per plot. The characteristic number and weight of fruits, total and commercial, percentage of commercial fruits and fruits weight were evaluated. The averages were compared by the Tukey test $(5 \%)$ and the evaluation of the inbreeding depression was done through regression analysis. The populations $S_{0}$ and $S_{1}$ were similar or superiors to 'Safira' in relation to the number of total fruits, total weight per plant and commercial weight per plant demonstrating the potential of this population to obtain a new cultivar or hybrid of the 'caipira' type. Reduction in fruit production (total and commercial) was observed in the $\mathrm{S}_{2}$ population and also in the subsequent generations of selfings due to a possible vigor loss.
\end{abstract}

Keywords: Cucumis sativus, inbreeding, yield.

(Recebido para publicação em 22 de julho de 2004 e aceito em 13 de maio de 2005)

$\mathrm{N}_{\mathrm{s}-2}^{\circ}$ o melhoramento genético utilizase a autofecundação para se obter uniformidade, sendo este recurso muito utilizado na obtenção de novas cultivares em Cucurbitáceas (COSTA; PINTO, 1977; PINK; WALKEY, 1985; PEIXOTO, 1987; NIENHUIS; LOWER, 1988; LOWER; EDWARDS, 1986; BAGGET; KEAN, 1990; JANSEN; JANSEN, 1990; DELLA VECCHIA et al., 1993).

Entretanto, a autofecundação aumenta a homozigose média das plantas e pode acarretar um efeito conhecido como "depressão endogâmica” em espécies alógamas. A depressão, propriamente dita, é uma diminuição na expressão de caracteres quantitativos, em decorrência do aumento da homozigose causada pela endogamia, (MIRANDA, 2001).

A causa da depressão endogâmica foi associada com a presença de alelos deletérios e letais em genótipos homozigóticos. Muitos alelos recessivos permanecem ocultos em condições heterozigotas nas populações naturais. À medida que a homozigose aumenta nas populações endogâmicas, existe uma probabilidade maior para as características recessivas, muitas das quais são deletérias, começarem a se manifestar, resultando em perda de vigor (ALLARD, 1971).

As Cucurbitáceas, sendo geralmente alógamas, são exemplos de um grupo de espécies em que certas linhagens parecem perder pouco vigor por endogamia. Acredita-se ainda, que após certo número de gerações de autofecundações e seleções, a planta recupera certas características desejáveis (ALLARD, 1971).

A literatura é contraditória quanto à perda de vigor causada por endogamia, em Cucurbitáceas. O processo de autofecundação durante dez gerações em Cucurbita maxima não afetou as características de vigor e capacidade reprodutiva (CUMMINGS; JENKINS, 1928). Bushnell (1922) estudando o efeito da endogamia em C. pepo, constatou que não ocorria necessariamente perda de vigor durante o processo de autofecundação.

Apesar de vários autores adotarem a hipótese de reduzida depressão por endogamia em Cucurbita, alguns resultados de pesquisas mostram depressão causada por endogamia para várias características em $C$. pepo e $C$. maxima (BORGHI, 1976; CHEKALINA, 1976).

Johansson et al. (1998) relataram redução na produção de frutos e na performance do pólen com a endogamia em C. texana. Também Stephenson et al. (2001) relataram que a endogamia pode afetar a qualidade do pólen em C. pepo.

Segundo Robinson (1999), têm sido desenvolvidas linhagens de pepino, abóbora, melão e melancia sem perda de vigor. A depressão por endogamia não é fator limitante para a produção de sementes híbridas em cucurbitáceas.

Apesar da presença da heterose e endogamia ser relatada para pepino in- 
dústria, Cramer e Wehner (1999) relataram que existe possibilidade de se obter linhagens tão boas quanto híbridos, com uma baixa depressão por endogamia. Entretanto, vários autores têm relatado heterose em pepino (GHADERI; LOWER, 1978; LOWER et al., 1982; FILGUEIRA et al., 1986; DELANEY; LOWER, 1987) o que pode justificar a adoção de híbridos F1.

O objetivo deste trabalho foi avaliar a perda de vigor com sucessivas gerações de autofecundações em uma população de pepino caipira.

\section{MATERIAL E MÉTODOS}

O experimento foi conduzido em campo, na UNESP, Campus de Botucatu, localizado no município de São Manuel (SP), em uma estufa, tipo arco, com $7 \mathrm{~m}$ de largura por $20 \mathrm{~m}$ de comprimento e pé direito de $1,8 \mathrm{~m}$, com cobertura de polietileno transparente de $75 \mu \mathrm{m}$ de espessura.

Utilizou-se uma população de pepino caipira originada do cruzamento entre Safira x Hatem. O híbrido resultante foi retrocruzado com o 'Safira' obtendo-se a população (Safira $\mathrm{x}$ Hatem) $\mathrm{x}$ Safira F1RC1. Estes cruzamentos foram realizados visando a incorporação da característica partenocarpia, presente no híbrido Hatem, em uma população do tipo caipira. Plantas desta população foram intercruzadas para obtenção da população F2RC1 que foi considerada a população inicial deste trabalho, denominada de população $S_{0}$, com coeficiente de endogamia de Wright igual a 0,25.

Cerca de 40 plantas da população $S_{0}$ foram autofecundadas para obtenção de progênies $S_{1}$ e a partir desta, obtiveramse as gerações $S_{2}, S_{3}, S_{4}$ e $S_{5}$, através de autofecundações sucessivas pelo método do SSD (Single Seed Descent $=$ descendência de semente única), de acordo com Brim (1966). Para obtenção da população $S_{1}$ foram misturadas sementes das 40 progênies desta geração, onde cada progênie foi representada pelo mesmo número de sementes. $\mathrm{O}$ mesmo foi feito para as demais gerações, sempre colocando igual número de sementes de cada progênie. Deste modo foram obtidas populações com 1 a 5 gerações sucessivas de autofecundação, ou seja, com diferentes graus de endogamia, a partir de amostras, ao acaso, de sementes das progênies $S_{1}$ a $S_{5}$. Com estas 6 gerações $\left(\mathrm{S}_{0}, \mathrm{~S}_{1}, \mathrm{~S}_{2}, \mathrm{~S}_{3}, \mathrm{~S}_{4}\right.$ e $S_{5}$ ) foram realizados os estudos de endogamia. Também foi utilizado o híbrido Safira como padrão de pepino do tipo caipira.

$\mathrm{O}$ experimento foi implantado no delineamento de blocos ao acaso, com sete tratamentos (seis gerações de autofecundação: $\mathrm{S}_{0}$ a $\mathrm{S}_{5}$ e o híbrido Safira), seis repetições e cinco plantas por parcela.

A semeadura foi realizada em bandejas de poliestireno expandido de 128 células (21/08/02) e o transplante realizado quando as plântulas apresentavam 2 folhas definitivas no dia 12/09/02. O espaçamento utilizado foi $1,0 \mathrm{~m}$ entre linhas e 0,5 m entre plantas.

Durante a condução da cultura, a área foi mantida livre de ervas daninhas através de capinas manuais e a irrigação foi realizada por gotejamento. A adubação de cobertura foi efetuada semanalmente com nitrato de cálcio ( $2 \mathrm{~g} /$ planta) a partir da primeira semana após o transplante e nitrato de potássio ( $2 \mathrm{~g} /$ planta) a partir do início da frutificação. O controle de pragas e doenças foi realizado de acordo com as necessidades da cultura, através de pulverizações com inseticida Decis ${ }^{\circledR}$ e o fungicida Rubigan ${ }^{\circledR}$.

Cada planta foi tutorada individualmente eliminando todas as brotações e flores até o $5^{\circ}$ nó da haste principal, desbrota das ramas laterais (após o $6^{\circ}$ nó da haste principal) entre a segunda e terceira folhas. Desbastou-se o meristema apical da planta quando este atingiu a altura do arame (cerca de 1,80 $\mathrm{m}$ de altura).

A colheita iniciou-se 39 dias após o transplante sendo realizada por 40 dias. Os frutos foram colhidos a cada dois dias, com cerca de $15 \mathrm{~cm}$ de comprimento, pesados e classificados em frutos comerciais ou não. $\mathrm{O}$ fruto considerado comercial não apresentava nenhum defeito visual aparente.

Foram avaliadas as características de peso de frutos totais, peso de frutos comerciais, número total de frutos, número de frutos comerciais, porcentagem de frutos comerciais e peso médio de frutos comerciais.
Foram realizadas análises de variância, para cada característica com transformações dos dados, quando necessárias. As médias das seis populações e do híbrido Safira foram comparadas pelo teste de Tukey (5\%), para verificar o potencial da população em relação ao híbrido comercial.

Também foram realizadas análises de variância apenas com as populações endogâmicas $\left(\mathrm{S}_{0}\right.$ a $\left.\mathrm{S}_{5}\right)$ e quando, nesta análise, o quadrado médio do tratamento foi significativo pelo teste F, significa que houve diferença estatística entre as gerações. Neste caso, foi feita análise de regressão, utilizando-se o número de gerações de autofecundações para medir o efeito da endogamia sobre as características avaliadas. Quando não houve diferença estatística pelo teste F, considerou-se não haver perda de vigor com as autofecundações sucessivas.

\section{RESULTADOS E DISCUSSÃO}

\section{Comparação das populações com o híbrido Safira}

As gerações $S_{0}$ e $S_{1}$ foram iguais ou superiores para as características número de frutos totais e comerciais, peso total por planta e peso comercial por planta quando comparadas ao híbrido Safira (Tabela 1), demonstrando o potencial desta população para obtenção de uma nova cultivar ou híbrido do tipo caipira. Destaca-se a maior produção total (número de frutos e peso) onde a população $S_{1}$ foi superior ao híbrido Safira, com uma produção de quatro frutos a mais por planta. Esta maior produção na população $S_{1}$ se deve à característica partenocarpia em segregação nesta população. Apesar de todos os materiais terem sido cultivados com a presença de abelhas, tendo a mesma facilidade de polinização, a característica partenocarpia permite que mesmo as flores femininas não polinizadas se desenvolvam em frutos. Não foi realizada comparação com o híbrido Hatem, que é partenocárpico, porque a característica desejada é tipo caipira. As demais populações $\left(\mathrm{S}_{2}\right.$ a $\left.\mathrm{S}_{5}\right)$ foram estatisticamente iguais ao híbrido comercial. Os valores obtidos para as características de produção por planta estão muito próximos do obtido por Cardoso (2002) no 
cultivo de inverno em São Manuel, onde o número de frutos total do híbrido Safira foi de 19,4, o número de frutos comerciais foi de 12,3 , a produção total de 3536 g e a produção comercial foi de 2633 g por planta.

O peso médio de frutos comerciais não diferiu estatísticamente entre todos os tratamentos (Tabela 1). O ponto de colheita foi aproximadamente o mesmo para todos os tratamentos, ou seja, frutos com cerca de $15 \mathrm{~cm}$ de comprimento. Entretanto, observou-se grande variação no comprimento e diâmetro dos frutos nas populações endogâmicas em relação ao híbrido Safira, uma vez que as populações foram obtidas com mistura de linhagens.

$\mathrm{Na}$ porcentagem de frutos comerciais não houve diferença entre os tratamentos, com valores oscilando entre 80,1 e $86,3 \%$, demonstrando que a população estudada apresenta potencial quando se compara ao híbrido Safira.

\section{Estudo da endogamia}

Para a característica peso médio de fruto comercial não observou-se perda de vigor com o aumento do número de autofecundações, o que já era esperado, pois o ponto de colheita foi aproximadamente o mesmo para todos os tratamentos. Também para porcentagem de frutos comerciais não se observou diferença entre as populações endogâmicas, demonstrando que as autofecundações sucessivas não afetaram o aspecto visual dos frutos produzidos.

No entanto, observou-se uma tendência de redução linear no valor das características número de frutos total, número de frutos comercial, peso total por planta e peso comercial por planta em função do número de autofecundações. Obteve-se uma redução média de 1,14 frutos por planta e de 0,95 frutos comerciais por planta a cada geração de autofecundação (Figura 1), correspondendo a uma redução de 196 e $179 \mathrm{~g}$ de frutos total e comercial por planta, respectivamente (Figura 2).

Portanto, observou-se acentuada perda de produção com o aumento da endogamia, discordando com o relatado por Cramer e Wehner (1999) em pepino e por Bushnell (1922) e Cummings e Jenkins (1928) em Cucurbita ssp. Deste modo, a probabilidade de serem obti-

Tabela 1. Número de frutos totais (NFT), número de frutos comerciais (NFC), peso total (PT), peso comercial (PC) por planta, peso médio de fruto comercial (PMFC) e porcentagem de frutos comerciais (FC) nas populações com diferentes graus de endogamia e no híbrido Safira. São Manuel, UNESP, 2002.

\begin{tabular}{lllllll}
\hline Tratamento & NFT & NFC & PT (g) & PC (g) & PMFC (g) & FC (\%) \\
\hline Safira & $17,4 \mathrm{bc}$ & $14,4 \mathrm{ab}$ & $2603 \mathrm{bc}$ & $2308 \mathrm{bc}$ & $161 \mathrm{a}$ & $82,4 \mathrm{a}$ \\
$\mathrm{S}_{0}$ & $18,7 \mathrm{ab}$ & $16,1 \mathrm{ab}$ & $2917 \mathrm{ab}$ & $2652 \mathrm{ab}$ & $168 \mathrm{a}$ & $85,5 \mathrm{a}$ \\
$\mathrm{S}_{1}$ & $21,4 \mathrm{a}$ & $17,7 \mathrm{a}$ & $3271 \mathrm{a}$ & $2874 \mathrm{a}$ & $163 \mathrm{a}$ & $82,9 \mathrm{a}$ \\
$\mathrm{S}_{2}$ & $15,7 \mathrm{bc}$ & $12,6 \mathrm{~b}$ & $2320 \mathrm{c}$ & $2014 \mathrm{c}$ & $159 \mathrm{a}$ & $80,1 \mathrm{a}$ \\
$\mathrm{S}_{3}$ & $15,5 \mathrm{bc}$ & $13,0 \mathrm{~b}$ & $2291 \mathrm{c}$ & $2028 \mathrm{c}$ & $154 \mathrm{a}$ & $84,2 \mathrm{a}$ \\
$\mathrm{S}_{4}$ & $15,1 \mathrm{bc}$ & $12,7 \mathrm{~b}$ & $2318 \mathrm{c}$ & $2048 \mathrm{c}$ & $162 \mathrm{a}$ & $82,3 \mathrm{a}$ \\
$\mathrm{S}_{5}$ & $14,5 \mathrm{c}$ & $12,5 \mathrm{~b}$ & $2120 \mathrm{c}$ & $1895 \mathrm{c}$ & $152 \mathrm{a}$ & $86,3 \mathrm{a}$ \\
\hline C.V. & $5,94 \%$ & $7,28 \%$ & $11,50 \%$ & $12,96 \%$ & $6,86 \%$ & $3,69 \%$ \\
\hline
\end{tabular}

Médias seguidas pela mesma letra, nas colunas, não diferem estatisticamente pelo teste de Tukey (5\%).

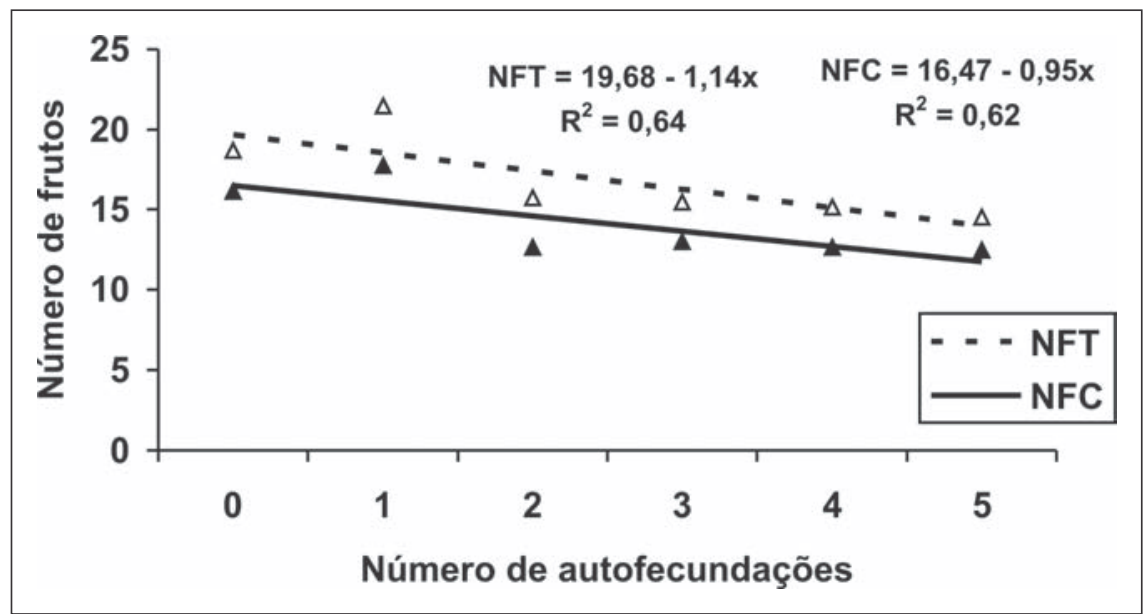

Figura 1. Número de frutos total (NFT) e comercial (NFC) por planta, em função do número de autofecundações. São Manuel, UNESP, 2002.

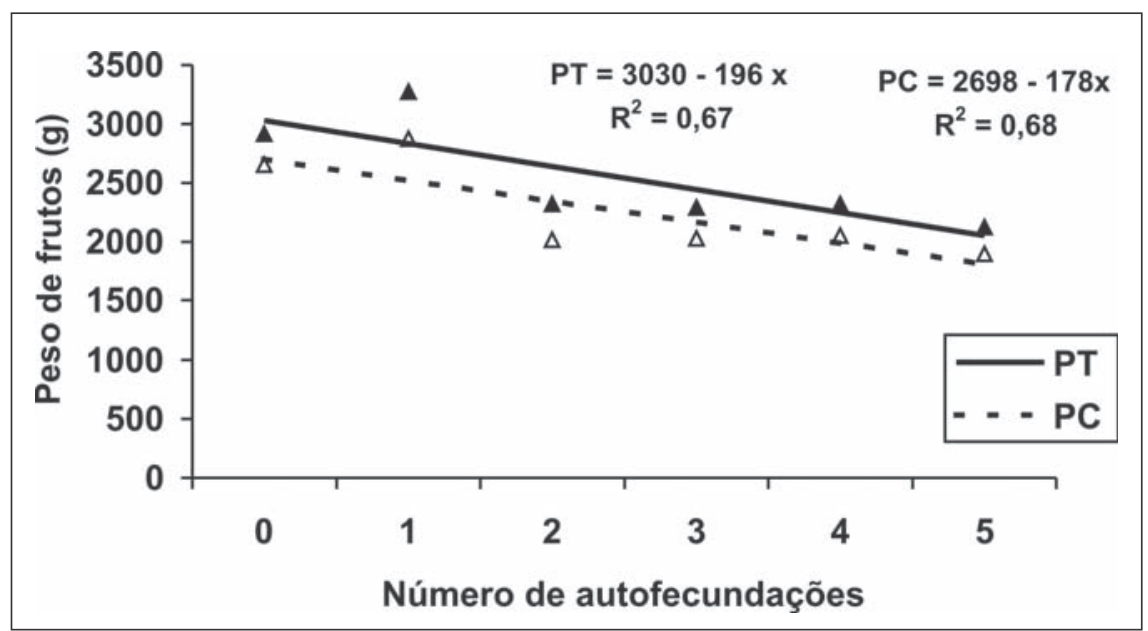

Figura 2. Peso (g) total (PT) e comercial (PC) por planta, em função do número de autofecundações. São Manuel, UNESP, 2002.

das progênies endogâmicas nesta população pelo método SSD com potencial produtivo superior à população original é baixa. Porém, ressalta-se que as po- pulações avaliadas foram obtidas pela mistura de progênies autofecundadas e, conforme Maluf (2001), diferentes linhas obtidas após certo número de ge- 
rações de autofecundação podem apresentar resultados diferentes em relação à perda de vigor.

Além da perda de vigor pela endogamia, a redução na produção de frutos pode ter outra explicação: redução na freqüência de plantas ginóicas com o aumento do número de autofecundações. No processo de autofecundações sucessivas é mais fácil manter plantas monóicas do que plantas ginóicas, mesmo com a aplicação de tiossulfato de prata. Plantas monóicas apresentam menor potencial produtivo que plantas ginóicas e quanto maior a proporção de flores masculinas em uma planta, menor será seu potencial produtivo.

Apesar da redução na produção com a endogamia, o vigor pode ser recuperado com a recombinação das melhores progênies ou com a obtenção de híbridos, principalmente porque a população apresenta potencial, sendo que as gerações $S_{0}$ e $S_{1}$ foram iguais ou superiores ao híbrido Safira. Heterose para produção de frutos em pepino já foi relatada por Ghaderi e Lower (1978); Filgueira et al. (1986) e Li et al. (1995).

Pode-se concluir que a população estudada apresenta redução linear na produção de frutos com as sucessivas autofecundações, o que inviabilizaria a utilização de linhagens diretamente como cultivares, entretanto, a qualidade de fruto não foi afetada.

\section{AGRADECIMENTOS}

À CAPES pela concessão de bolsa de mestrado à primeira autora.

\section{LITERATURA CITADA}

ALLARD, R.W. Princípios do melhoramento genético das plantas. São Paulo: Edgard Blücher, 1971. $381 \mathrm{p}$.
BAGGETT, J.R.; KEAN, D. 'Sugar Loaf' and "Honey Boat" winter squashes. HortScience, Alexandria, v.25, n.3, p.369-370, 1990.

BORGHI, B. Evaluation of heterosis in Cucurbita pepo L. IN: JÁNOSSY, A.; LUPTON, F.G.H. (Ed.). Heterosis in plant breeding proceedings. New York: Elsevier, 1976. p.219-225 (Congress of Eucarpia, 7).

BRIM, C.A. A modified pedigree method of selection in soybeans. Crop Science, Madison, v.6, p.220, 1966.

BUSHNELL, J.W. Isolation of uniform types of hubbard squash by inbreeding. Proceedings of the American Society for Horticultural Science, Alexandria, v.19, p.139-144, 1922.

CARDOSO, A.I.I. Avaliação de cultivares de pepino tipo caipira sob ambiente protegido em duas épocas de semeadura. Bragantia, Campinas, v.61, n.1, p.43-48, 2002.

CHEKALINA, I.N. Effect of inbreeding on variability of cucurbits (Cucurbita maxima Duch and Cucurbita pepo L.) Genetika, Praga, v.12, p.45-49, 1976.

COSTA, C.P.; PINTO, C.A.B.P. Melhoramento de hortaliças. Piracicaba: ESALQ/USP, 1977.319 p. CRAMER, C.S.; WEHNER, T.C. Little heterosis for yield and yield components in hybrids of six cucumber inbreds. Euphytica, Wageningen, v.110, n.2, p.99-108, 1999.

CUMMINGS, M.B.; JENKINS, E.W. Pure lines studies with ten gerations of hubbard squash. Vermont Agricultural Experiment Station Bulletin, Vermont, v.280, p.1-29, 1928.

DELANEY, D.E.; LOWER, R.L. Generation means analysis of plant characters in crosses between two determinate cucumber lines and Cucumis sativus var. hardwickii. Journal of the American Society for Horticultural Science, Alexandria, v.112, n.4, p.707-711, 1987.

DELLA VECCHIA, P.T.; TERENCIANO SOBRINHO, P.; TERENCIANO, A. Breeding bush types of C. moschata with field resistance to PRSV-w. Cucurbit Genetics Cooperative, Maryland, v.16, p.70-71, 1993.

FILGUEIRA, F.A.R.; GIORDANO, L.B.; FERREIRA, P.E.; VECCHIA, P.T.D. Avaliação de híbridos F1 de pepino do tipo caipira. Horticultura Brasileira, Brasília, v.4, n.1, p.1720, 1986.

GHADERI, A.; LOWER, R.L. Heterosis and phenotypic stability of F1 hybrids in controlled environment. Journal of the American Society for Horticultural Science, Alexandria, v.103, p.275278,1978.

JANSEN, R.C.; JANSEN, J. On the selection for specific genes by single seed descent. Euphytica, Wageningen, v.51, n.2, p.131-140, 1990.
JOHANNSSON, M.H.; GATES, M.J.; STEPHENSON, A.G. Inbreeding depression affects pollen performance in Cucurbita texana. Journal of Evolutionary Biology, Basel, v.11, p.579-588, 1998.

LI, J.W.; LI, J.W.; WEI, Z.D. Genetic analysis for major agronomic characters in cucumber (Cucumis sativus L.). Acta Horticulturae, The Hague, n.402, p.388-391, 1995.

LOWER, R.L.; EDWARDS, M.D. Cucumber breeding. In: BASSET, M.J. (Ed.). Breeding vegetable crops. Westport: Avi Publishing, 1986. p.173-207.

LOWER, R.L.; NIENHUIS, J.; MILLER, C.H. Gene action and heterosis for yield and vegetative characteristics in a cross between a gynoecious pickling cucumber inbred and Cucumis sativus var. hardwickii line. Journal of the American Society for Horticultural Science, Alexandria, v.107, p.7578, 1982.

MALUF, W.R. Heterose e emprego de híbridos F1 em hortaliças. In: NASS, L.L. Recursos genéticos e melhoramento: plantas. Rondonópolis: Fundação MT, 2001. p.237-356.

MIRANDA, J.B.F. Endogamia e consanguinidade. In: NASS, L.L. Recursos genéticos e melhoramento: plantas. Rondonópolis: Fundação MT, 2001. p.629-647.

NIENHUIS, J.; LOWER, R.L. Comparison of two recurrent selection procedures for yield in two pickling cucumber populations. Journal of the American Society for Horticultural Science, Alexandria, v.113, n.2, p.272-276, 1988.

PEIXOTO, N. Melhoramento genético de abóbora (Cucurbita moschata Duchesne) do grupo Baianinha: I. Obtenção, seleção de linhagens e avaliação de híbridos $F_{1}$ braquíticos. $1987.110 \mathrm{f}$. Dissertação (Mestrado em genética e melhoramento) - Universidade Federal de Viçosa, Viçosa, 1987.

PINK, D.A.C.; WALKEY, D.G.A. Breeding for resistance to cucumber mosaic virus in courgette and vegetable marrow. Cucurbit Genetics Cooperative, Maryland, v.8, p.74-75, 1985.

ROBINSON, R.W. Rationale and methods for producing hybrid cucurbit seed. Journal of New Seeds, v.1, p.1-47, 1999.

STEPHENSON, A.G.; HAYES, C.N.; JOHANNSSON, M.H.; WINSOR, J.A. The performance of microgametophytes is affected by inbreeding depression and hybrid vigor in the sporophytic generation. Sexual Plant Reproduction, v.14, p.77-83, 2001. 